\title{
Reflux oesophagitis and oesophageal transit: evidence for a primary oesophageal motor disorder
}

\author{
C A ERIKSEN, S A SADEK, C CRANFORD, D SUTTON, N KENNEDY, \\ AND A CUSCHIERI
}

From the Departments of Surgery and Nuclear Medicine, Ninewells Hospital and Medical School, Dundee

\begin{abstract}
SUMmary Patients with reflux oesophagitis have a diminished capacity for distal oesophageal clearance. This is considered to be secondary to acid reflux damage to the oesophageal wall. We have postulated that the observed oesophageal dysmotility is a primary phenomenon. Using 24 hour oesophageal pH monitoring and the solid bolus oesophageal egg transit test, we evaluated the oesophageal transit of 55 patients, with symptomatic reflux oesophagitis, and 16 healthy volunteers. The transit for the entire oesophagus was significantly prolonged in the patient group. This delay was evident in all three segments of the oesophagus. Amongst the patients, there was significant correlation between the oesophageal transit time and the number of prolonged reflux events. No correlation was found, however, between symptom score or severity of endoscopic oesophagitis and transit time. These results would indicate that the oesophageal dysmotility is an integral part of gastrooesophageal reflux disease, and is more of a cause than an effect.
\end{abstract}

Gastrooesophageal reflux disease and its complications are common clinical problems. The pathogenesis is presumed to be multifactorial. After a reflux episode, the gastric juice and other secretions are mainly cleared from the distal oesophagus by the primary peristaltic waves of the oesophageal body. The small amount of residual refluxate that coats the mucosa of the distal oesophagus is neutralised by swallowed saliva. ${ }^{1}$ Patients with chronic reflux and symptomatic reflux oesophagitis have a diminished capacity for acid clearance. ${ }^{2}$ It is generally thought that this oesophageal dysmotility results from reflux damage to the oesophageal wall, and is therefore a secondary phenomenon. Proof for this assertion, however, is lacking.

In this study, we have evaluated quantitative oesophageal transit of a solid bolus in a cohort of patients with gastrooesophageal reflux disease and compared their findings with those obtained in a group of asymptomatic volunteers.

The development of the oesophageal egg transit (OET) test, ${ }^{3}$ which measures the transit time of a

Address for correspondence: Professor A Cuschieri. Department of Surgery, Ninewells Hospital and Medical School, Dundee DD1 9SY.

Received for publication 9 October 1987. standardised solid bolus of $99 \mathrm{~m}$ Tc labelled poached egg white through the three segments of the oesophagus, has enabled us to investigate the relationship between oesophageal dysmotility and gastrooesophageal reflux.

\section{Methods}

PATIENTS

Fifty five patients ( 27 men) with a mean age of $50 \cdot 5$ years (range 18-78) who had symptomatic reflux oesophagitis were studied. Clinical evidence of oesophagitis and/or acid reflux was obtained in all patients by upper gastrointestinal endoscopy (with oesophageal mucosal biopsy) and 24 hour ambulatory oesophageal $\mathrm{pH}$ monitoring respectively.

Sixteen healthy volunteers (nine men) with a mean age of 40.4 years (range 27-69) constituted the control group. They were all free from symptoms of gastrooesophageal reflux, and had no past history of oesophageal, gastric or duodenal disease.

SYMPTOM SCORE

Symptoms related to gastrooesophageal reflux, namely heartburn, regurgitation and dysphagia, were scored on a scale $0-3$ depending on severity 


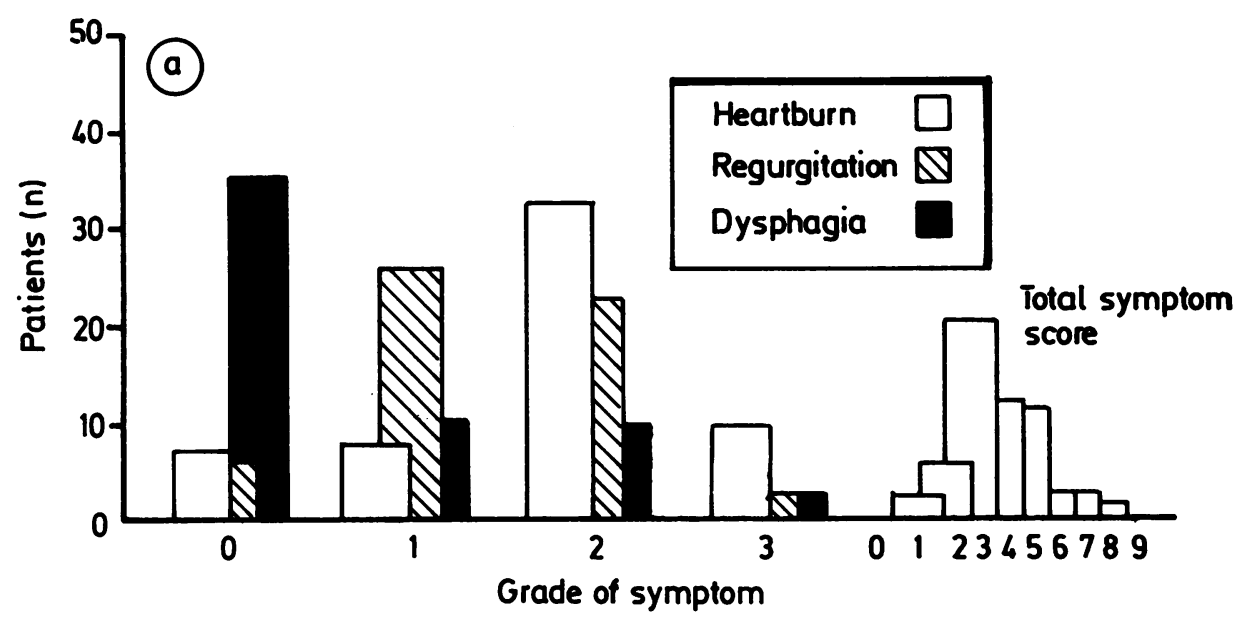

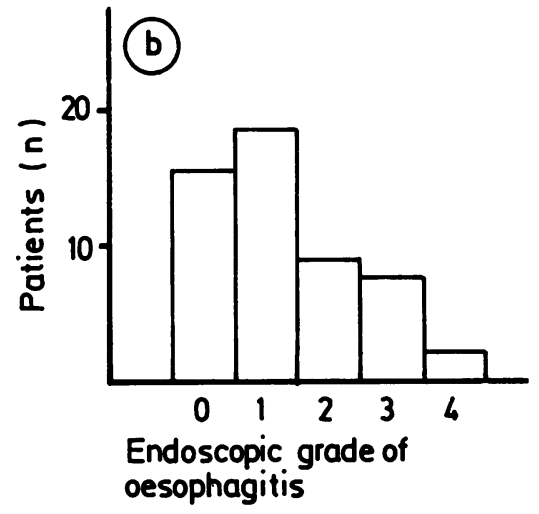

(Fig. 1a). Grade 2 heartburn was experienced in 32 $(58 \%)$ patients. Twenty five $(45 \%)$ patients complained of occasional regurgitation, while $34(62 \%)$ patients were not troubled with dysphagia. Twenty $(36 \%)$ of the 55 patients had a total symptom score of 3 .

UPPER GASTROINTESTINAL ENDOSCOPY The severity of oesophagitis, as observed by endoscopy, was graded from 0 -IV; 0 indicating a normal mucosa, I mild oesophagitis with erythema and friability, and IV being circinate ulceration with or without complications (Fig. 1b). Oesophageal mucosal biopsy was carried out, and the stomach and duodenum were inspected for any concommitant disease.

Oesophagitis was diagnosed in $38(70 \%)$ patients; this being of Grade I severity in $19(50 \%)$ of these patients. One patient failed to undergo endoscopy. Concommitant gastric and duodenal ulcers were encountered in three and five patients respectively. Four patients were also found to have duodenitis.
Fig. 1 Frequency histogram of the symptom score grades (a) and range of severity of oesophagitis (b) as assessed by endoscopy in the patients with reflux oesophagitis.

24 HOUR AMBULATORY OESOPHAGEAL PH All patients underwent examination by oesophageal manometry using a triple lumen perfused catheter system and the slow pull-through technique ${ }^{4}$ to determine the exact location of the high pressure zone (HPZ, lower oesophageal sphincter). A pH radio-pill (7006 Remote Control Systems, London) was positioned $5 \mathrm{~cm}$ cephalad to the HPZ, and a 24 hour oesophageal $\mathrm{pH}$ profile was obtained using a portable microlog receiving unit (Medical Physics, Ninewells Hospital and Medical School) with a sampling interval of 10 seconds. The data collected was offloaded to an IBM computer for analysis.

\section{OESOPHAGEAL EGG TRANSIT (OET)}

On a separate day, the solid bolus oesophageal transits of the patients and volunteers were quantitatively evaluated with the oesophageal egg transit test. This entailed the patient, in the erect posture, chewing then swallowing $10 \mathrm{ml}$ poached egg white, that had been labelled with $15-20 \mathrm{MBq}$ of technetium sodium pertechnetate. Serial one second 
frames were taken by a scintillation camera for a total of four minutes, and stored in an online computer. Activity versus time curves, quantifying the passage of the labelled egg white, were generated for the proximal, middle, and distal thirds as well as the entire oesophagus. A computer generated condensed image $e^{5}$ was also used to aid in the interpretation of the results. In the control group, the test was repeated after an interval of three to four weeks to assess the reproducibility of the transit time in each individual.

\section{STATISTICAL ANALYSIS}

The data were analysed using Mann-Whitney U-test, Wilcoxon's matched-pairs signed test, Spearman's rank correlation test, and Kendall Tau rank correlation test.

\section{Results}

Twenty four hour ambulatory oesophageal $\mathrm{pH}$ monitoring revealed that $43(78 \%)$ patients had abnormal pH profiles. Seventeen $(40 \%)$ of these patients were 'combined refluxers' - that is, refluxed in both erect and supine postures, while $13(30 \%)$ patients experienced reflux of acid only when in the erect posture. The acid exposure of the distal oesophagus at $\mathrm{pH}$ levels of $<2,<3$, and $<4$ are shown in Table 1 , and the acid reflux event analysis results are shown in Table 2 . Twelve patients exhibited normal oesophageal $\mathrm{pH}$ profiles but eight of these patients $(67 \%)$ showed mild oesophagitis at endoscopy while the remaining four were diagnosed as Grade II oesophagitis.

The oesophageal transit times for the patient and control groups are shown in Table 3. The total oesophageal transit time of the patients was $50 \cdot 0$ (10-240) seconds (median, range), and was significantly prolonged compared with the control group $(9 \cdot 5,8 \cdot 0-15 \cdot 7)$ seconds $(p<0 \cdot 0001)$. This delay in transit was distributed throughout the entire oesophagus, but was more marked in the middle and distal thirds and was significant in each segment. The normal aboral slowing in transit was not evident

Table 1 Frequency distribution of total pH data in the distal oesophagus in patients with reflux oesophagitis

\begin{tabular}{cll}
\hline$p H$ Posture & $\begin{array}{l}\text { Cumulative\% data } \\
\text { Median }(\text { range })\end{array}$ & $\begin{array}{l}\text { Normal range } \\
\text { Median }(\text { range })\end{array}$ \\
\hline$<2$ Erect & $0 \cdot 3(0 \cdot 0-33 \cdot 2)$ & $0 \cdot 1(0 \cdot 0-3 \cdot 5)$ \\
Supine & $0 \cdot 1(0 \cdot 0-6 \cdot 0)$ & $0 \cdot 0(0 \cdot 0-1 \cdot 1)$ \\
$<3$ Erect & $2 \cdot 8(0 \cdot 0-40 \cdot 9)$ & $0 \cdot 8(0 \cdot 0-5 \cdot 4)$ \\
Supine & $1 \cdot 1(0 \cdot 0-45 \cdot 6)$ & $0 \cdot 1(0 \cdot 0-3 \cdot 1)$ \\
<4 Erect & $8 \cdot 6(0 \cdot 0-55 \cdot 7)$ & $2 \cdot 3(0 \cdot 0-14 \cdot 8)$ \\
Supine & $4 \cdot 1(0 \cdot 0-67 \cdot 0)$ & $0 \cdot 1(0 \cdot(0-10 \cdot 6)$ \\
\hline
\end{tabular}

Table 2 Acid reflux event analysis to $\mathrm{pH}<4$ in patients with reflux oesophagitis

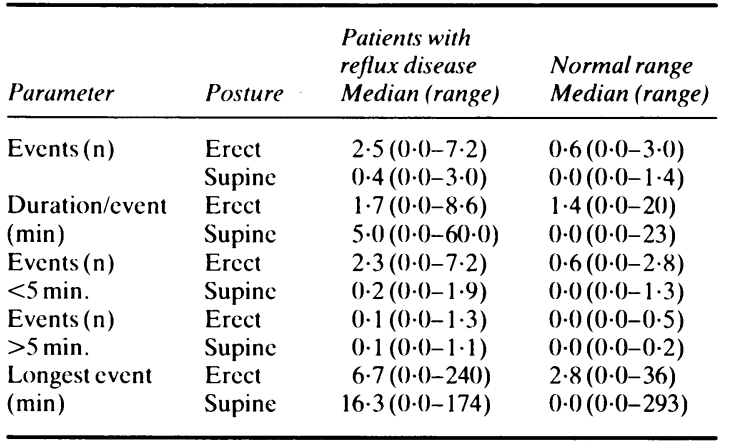

(Data standardised to one hour.)

Table 3 Oesophageal egg transit times for reflux oesophagitis patients and normal volunteers

\begin{tabular}{|c|c|c|c|}
\hline $\begin{array}{l}\text { Oesophageal } \\
\text { transit } \\
(\text { sec })\end{array}$ & $\begin{array}{l}\text { Patients with } \\
\text { reflux disease } \\
(n=55) \\
\text { Median (range) }\end{array}$ & $\begin{array}{l}\text { Normal } \\
\text { volunteers } \\
(n=16) \\
\text { Median (range) }\end{array}$ & $\begin{array}{l}p \text { value } \\
\text { (Mann-Whitney } \\
\text { U-test) }\end{array}$ \\
\hline Total & $50 \cdot 0(10-240)$ & $9 \cdot 5(8-15 \cdot 7)$ & $<0 \cdot 0001$ \\
\hline Prox third & $12 \cdot 0(3-240)$ & $4 \cdot 2(3-7 \cdot 5)$ & $<0 \cdot 0001$ \\
\hline Mid third & $38 \cdot 0(6-240)$ & $6 \cdot 5(4-9 \cdot 5)$ & $<0 \cdot(0001$ \\
\hline Dist third & $35 \cdot 0(6-240)$ & $8 \cdot 2(6-13)$ & $<0 \cdot 0001$ \\
\hline
\end{tabular}

throughout the whole oesophagus in the patient group, although the transit through the middle third was significantly slower than that through the proximal third $(\mathrm{p}<0.005)$. The middle third transit was longer, though not significantly so, than through the distal third; median times being 38.0 and 35.0 seconds respectively.

There was significant correlation between the total oesophageal transit time and the number of long lived acid reflux events $(\mathrm{rho}=0 \cdot 274, \mathrm{p}<0.05)$. This parameter, together with the duration of reflux events and the time of the longest reflux event, expresses the clearing ability of the distal oesophagus. There was, however, no significant correlation between the transit time and those oesophageal $\mathrm{pH}$ data pertaining to high pressure zone incompetence - that is, number of reflux events $($ rho $=1.334)$, and number of short lived reflux events ( $r h o=0 \cdot 083$ ).

The times of oesophageal transit did not correlate significantly with the severity of the reflux symptoms: heartburn score (Tau 0.047), regurgitation score (Tau 0.139), dysphagia score $($ Tau $=0 \cdot 180)$, (Fig. 2 ). The correlation between the oesophageal transit time and the endoscopic grading proved also to be not significant $(\mathrm{Tau}=0 \cdot 008)$. 

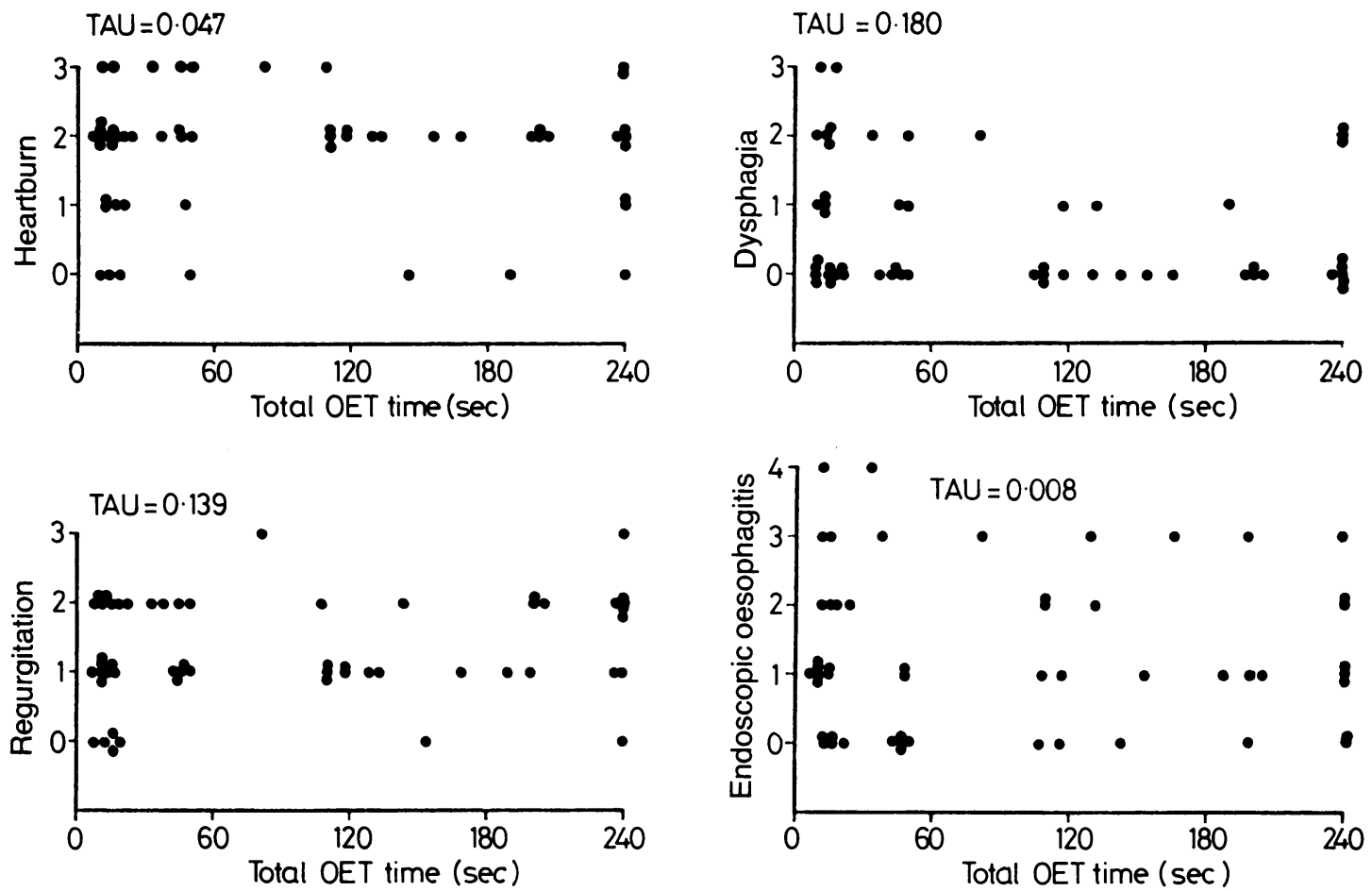

Fig. 2 Correlation of the total oesophageal egg transit (OET) time and symptom grading and endoscopic severity grades.

\section{Discussion}

The pathogenesis of gastrooesophageal reflux disease has been the subject of numerous studies during the past two decades. Among the list of contributing factors are an incompetent high pressure zone (lower oesophageal sphincter), diminished resistance of oesophageal mucosa to injury, the amount and composition of refluxate, and a defective distal oesophageal clearing mechanism. ${ }^{267}$ It is generally agreed that the integrity of the high pressure zone is the most important of these factors, ${ }^{27}$ and this is emphasised by the favourable results obtained with the fundoplication and other antireflux operations.

The distal oesophagus is emptied of its refluxed contents by the action of primary peristaltic waves in the oesophageal body, and it is generally believed that this is the dominant mechanism of oesophageal clearance. ${ }^{189}$

We have previously reported the technique of the oesophageal egg transit (OET) test, ${ }^{3}$ which enables objective quantitation of solid bolus oesophageal transit. The reproducibility of the test in the normal subjects is good (correlation coefficient $=0 \cdot 85$, coefficient of variation $14 \%$ ), and it clearly differen- tiates patients with oesophageal disease from the normal. Thus, although oesophageal manometry was carried out in this study, it was used to determine the location of the high pressure zone rather to assess the oesophageal motility.

The findings of the OET test in this study have shown a significant delay in the transit of a solid bolus throughout the entire oesophagus in patients with reflux oesophagitis when compared with the controls. This delay was more prominent in the middle and distal thirds than in the proximal segment of the oesophagus. Furthermore, patients with reflux disease did not show the normal aboral slowing of oesophageal transit. These results confirm the manometrically demonstrated abnormal primary peristalsis previously reported in reflux patients, ${ }^{10} 11$ and the transit abnormalities encountered using radioisotope labelled liquid boluses. ${ }^{12}$

Further manometric studies have shown an impairment of the clearing capacity of the distal oesophagus in the presence of reflux oesophagitis; a significant decrease in the peristaltic activity of the distal oesophagus being found..$^{913}$ This clearing capacity of the oesophagus can be studied using the analysis of the 24 hour oesophageal $\mathrm{pH}$ profile. It correlates with the duration of reflux events, the number of pro- 
longed reflux events and the time of the longest reflux event. Our results show a significant correlation between the total oesophageal transit time and the number of long lived events in reflux patients.

The lack of correlation between the transit times and the severity of either the reflux symptoms or endoscopic grading of oesophagitis is an important observation. This suggests that, instead of being a complication of gastrooesophageal reflux, the dysmotility of the oesophagus is an integral part of the disease process. It would then appear that this abnormality is part of the primary multifactorial aetiology of gastrooesophageal reflux disease, rather than being a secondary phenomenon. This hypothesis is strengthened by the observation that the delay in the oesophageal transit was not restricted to the area of endoscopically determined reflux induced oesophageal damage. Indeed, significant delay was encountered in these patients in respect of transit through the upper and middle thirds of the oesophagus and this was independent of any holdup at the lower end of the oesophagus. The additional finding that the slowest transit occurred in the middle third also lends support to the postulated primary nature of the oesophageal motor disorder.

\section{References}

1 Ferguson MK, Ryan JW, Little AG, et al. Oesophageal emptying and acid neutralization in patients with symptoms of oesophageal reflux. Ann Surg 1985; 201: 728-35.

2 Nelson JL, Castell DO. Reflux oesophagitis: an update. South Med J 1985; 78: 452-7.
3 Cranford CA, Sutton D, Sadek SA, Kennedy N, Cuschieri A. New physiological method of evaluating oesophageal transit. BrJ Surg 1987; 74: 411-5.

4 Welch RW, Drake JT. Normal lower esophageal pressure: A comparison of rapid versus slow pullthrough techniques. Gastroenterology 1980; 78: 1446-51.

5 Klein HA, Wald A. Computer analysis of radionuclide oesophageal transit studies. J Nucl Med 1984; 25: 957-64.

6 Cortesini C, Marcuzzo G, Pucciani F. Relationship between mixed acid-alkali gastro-oesophageal reflux and oesophagitis. Ital J Surg Sci 1985; 15: 9-15.

7 Styles CB, Holt S, Bowes KL, et al. Gastro-oesophageal reflux and transit scintigraphy: a comparison with oesophageal biopsy in patients with heartburn. J Can Assoc Radiol 1984; 35: 124-7.

8 Corazziari E, Bontempo I, Anzini F, et al. Motor activity of the distal oesophagus and gastro-oesophageal reflux. Gut 1984; 25: 7-13.

9 Baldi F, Ferrarini F, Balestra R, et al. Oesophageal motor events at occurence of acid reflux and during endogenous acid exposure in normals and patients. Gut 1985; 26: 336-41.

10 Olsen AM, Schlegal JF. Motility disturbances caused by oesophagitis. J Thor Cardiovasc Surg 1965; 50: 607-12.

11 Baldi F, Ferrarini F, Cassan, M, et al. Manometric evaluation of the oesophageal peristalsis and of the lower oesophageal sphincter in reflux oesophagitis. Ital J Gastroenterol 1982; 14: 145-9.

12 Tolin RD, Malmud LS, Reilley J, et al. Esophageal scintigraphy to quantitate esophageal transit (Quantitation of esophageal transit). Gastroenterology 1979; 76: 1402-8.

13 Stanciu C, Bennett JR. Oesophageal acid clearing: one factor in the production of reflux oesophagitis. Gut 1974; 15: 852-7. 